\title{
A REMARCAÇÃO DO PARÂMETRO DO SUJEITO NULO E SUAS REPERCUSSṌES NO PB: UM ESTUDO SOBRE AS SENTENÇAS EXISTENCIAIS
}

\author{
THE PARAMETRIC CHANGE IN THE NULL SUBJECT PARAMETER AND ITS \\ REPERCUTISSION IN PB: A STUDY OF EXISTENTIAL SENTENCES
}

\author{
Juliana Marins \\ Universidade Federal do Rio de Janeiro \\ juespmarins@hotmail.com
}

\begin{abstract}
RESUMO: Partindo das mudanças pelas quais o português brasileiro tem passado, quanto à remarcação do Parâmetro do Sujeito Nulo, investigo as sentenças existenciais com os verbos haver e ter no PB e no PE. A investigação é feita com base em duas amostras de peças de teatro popular, escritas entre 1840 e 1998. Tomando como base teórica a Teoria de Princípios e Parâmetros na perspectiva do Programa Minimalista (CHOMSKY 1995) e aplicando a metodologia comumente utilizada nos trabalhos apoiados na teoria de Variação e Mudança, o objetivo deste trabalho é mostrar como a substituição de haver por ter nesse tipo de estrutura tem relação com a perda da possibilidade de o sistema do PB licenciar uma categoria vazia na posição estrutural de sujeito, o que não se verifica no português europeu (PE). A análise revela que o verbo possessivo ter passou a invadir os contextos antes ocupados por haver, tornando-se o verbo existencial prototípico.
\end{abstract}

PALAVRAS-CHAVE: Sentenças Existenciais. Parâmetro do Sujeito Nulo. Pro-Drop.

ABSTRACT: Considering the changes that Brazilian Portuguese has been gone through about the Null Subject Parameter remarking, I investigate existential sentences with verbs haver and ter in BP and EP. The research is based on a corpus of popular plays, written between 1840 and 1998. Based on the Theory of Principles and Parameters in the perspective of the Minimalist Program (CHOMSKY 1995), and applying the methodology commonly used in the theory of linguistic variation and change, the objective is to show how the replacement of haver by ter in this type of structure is related to the loss of the possibility of licensing an empty category in the subject position, which is not the case in European Portuguese (EP). The analysis reveals that the possessive verb has started to invade the contexts once occupied by haver, and became the prototypical existential verb KEYWORDS: Existential Sentences. Subject Null Parameter. Pro-Drop.

\section{INTRODUÇÃO}

Nas últimas três décadas, inúmeros trabalhos sobre a representação do sujeito pronominal no português do Brasil (PB) mostraram as diferenças estruturais entre essa variedade do português e outras línguas românicas, como o espanhol, o italiano e mesmo a variedade 
portuguesa. De fato, tais trabalhos (DUARTE 1993, 1995, 2003, 2012; SOARES DA SILVA 2006; e MARINS 2009; entre outros), através de análises empíricas, indicam que o PB está passando por um processo de mudança no que se refere ao Parâmetro do Sujeito Nulo (PSN): a príncipio, o PB se comportava como uma língua de sujeito nulo (LSN) prototípica, dentro do grupo românico, revelando, entre outras propriedades, preferência pela posição de sujeito vazia, como acontece com o português europeu (PE). Posteriormente, observa-se que o PB veio apresentando comportamentos mais alinhados com as línguas de sujeito não-nulo (LSNN), como o inglês e o francês, preferindo o preenchimento da posição estrutural de sujeitos referenciais em todas as pessoas gramaticais.

Não só os sujeitos de referência definida são afetados pela mudança na marcação do PSN no PB: atestam-se alterações na representação dos sujeitos de referência arbitrária, segundo Duarte (1995), Cavalcante (1999, 2006), Santana (2010), entre outros. Numa evidência do que Weinreich, Lavov e Herzog (2006 [1968]) chamam "encaixamento" da mudança, a solução encontrada pelo sistema para que se evitasse a posição de sujeito vazia foi a emergência de estratégias alternativas de indeterminação do sujeito, com a realização, sobretudo, das formas você e a gente genéricos, como se vê nos exemplos (1) e (2) a seguir, extraídos de Santana (2010, p. 72):

(1) Tem uma outra técnica, que é muito usada, hoje em dia. O segredo é não se importar. Se você não se importar, você acaba dormindo. Mas você precisa não se importar de verdade. [Como encher um biquíni selvagem - 1992 Miguel Falabella]

(2) Velório, funeral, são rituais necessários Função, catártica, sabe, Francis? Além do mais, eu descobri que a gente não chora a morte do outro, a gente chora a própria morte. [A Partilha - 1990 - Miguel Falabella]

Finalmente, estudos mostram que, a partir do séc. XIX, no PB, o verbo possessivo ter começa a tomar corpo na representação da existência, invadindo um contexto anteriormente dominado pelo verbo haver. Estudos como o de Callou e Avelar (2000) confirmam no PB contemporâneo a hegemonia de ter existencial, restando a haver os casos em que o argumento interno exibe o traço [+abstrato], como ilustrado em (3 a,b) (Cf. CALLOU e AVELAR, 2000):

(3) a.[...]não há vantagem assim de imediato[...]

b.[...] não há tempo para que ele participe de atividades [...]

Interessa-me, particularmente, a ideia de Avelar (2006) de que haver teria deixado a lista dos itens funcionais e teria passado a fazer parte da lista dos itens substantivos, nos termos da Morfologia Distribuída (EMBICK e NOYER 2004). O autor apresenta dados empíricos que evidenciam tal processo, cujo resultado é a predominância de ter, verbo existencial funcional. $\mathrm{O}$ autor reforça a relação entre as alterações no quadro pronominal 
no $\mathrm{PB}$, o enfraquecimento da concordância e a incapacidade de o sistema licenciar uma categoria vazia $(c v)$ na posição estrutural de sujeito de sentenças existenciais com haver, dada a mudança no estatuto categorial desse verbo. Eu parto dessa perspectiva para analisar a substituição de haver por ter, buscando comparar os resultados da análise que proponho com aqueles apresentados por Avelar (2006), com base em Callou e Avelar (2000).

Visto isso, a proposta deste trabalho é investigar a entrada do verbo possessivo nos contextos existenciais ao longo do tempo, buscando compreender que razões teriam permitido a substituição de uma forma pela outra e a relação desse processo com a remarcação do PSN no PB, fato que não ocorre no PE que, por conseguinte, mantém haver como o prototípico representante da existência. Para isso, utilizo dados empíricos, extraídos de peças teatrais brasileiras e portuguesas, escritas ao longo dos séc. XIX e XX, no intuito de fornecer evidências na diacronia para as afirmações de Avelar (2006), reafirmando que o processo em análise é um "efeito colateral" da mudança que se opera no PB quanto à representação do sujeito pronominal. A análise permitirá ainda observar, então, de que mecanismos o PE dispõe para a representação da existência.

Basicamente, eu uso a Teoria de Princípios e Parâmetros, na sua versão minimalista (CHOMSKY 1995) para justificar o fato de que, no PB, passam a existir sentenças a partir das derivações mais econômicas no sentido de satisfazer as condições do EPP de $\mathrm{T}^{1}$. Além disso, a noção de "encaixamento" vem do modelo de estudo da mudança de Weinreich, Labov e Herzog (2006 [1968]), que integra o quadro teórico-metodológico que guia este estudo, estando tal noção forçosamente presente na busca de evidências de um processo de mudança efetivamente em curso.

O trabalho está organizado da seguinte maneira: na primeira seção, apresento o trabalho de Duarte (1993), sobre o comportamento do sujeito pronominal de referência definida à luz de dados diacrônicos oriundos de peças teatrais - base para as diretrizes teóricometodológicas da análise que eu proponho. Em seguida, mostro as ideias de Avelar (2006) sobre a mudança no estatuto categorial de haver e a relação desse processo com a remarcação do PSN. Na terceira seção, apresento a análise dos dados de PB e de PE, comparando os resultados de PB com os apresentados por Avelar (2006). Por fim, apresento as considerações finais, indicando brevemente, uma possível repercussão desse processo.

\section{UM ESTUDO DIACRÔNICO SOBRE OS SUJEITOS REFERENCIAIS: DUARTE (1993)}

\footnotetext{
${ }^{1}$ EPP (Extended Projection Principle ou Princípio da Projeção Extendida) de T(ense).
} 
Em estudo diacrônico sobre a representação do sujeito pronominal no PB, Duarte (1993), examinando peças teatrais dos séc. XIX e XX divididas em sete períodos, apresenta indícios de uma mudança na marcação paramétrica no sentido do preenchimento. Esse processo seria consequência do enfraquecimento da morfologia verbal (DUARTE 1993, 1995, 2003), devido às mudanças no quadro pronominal do PB.

O Gráfico 1, adaptado de Duarte (1993), mostra a progressiva redução no percentual de sujeitos nulos nas peças analisadas.

Gráfico 1: Sujeito nulo nas peças teatrais dos séc. XIX e XX

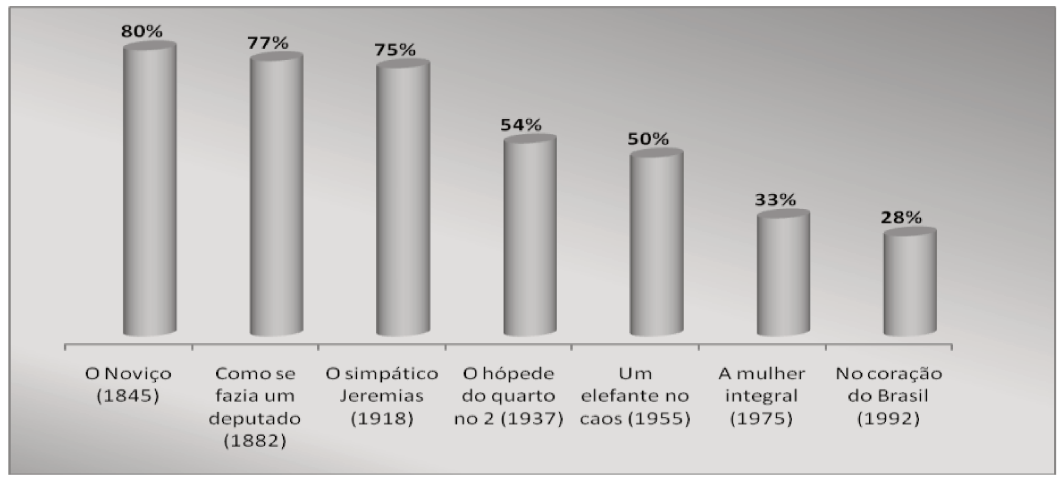

Fonte: Adaptado de Duarte (1993).

Podem-se identificar dois momentos em que houve uma redução significativa no percentual de sujeitos nulos: a partir da terceira década do século XX e no último quarto do mesmo século. Para justificar essa situação, entra em jogo a relação entre a mudança do sistema pronominal, o enfraquecimento da morfologia verbal e a identificação do sujeito nulo. A autora observou que nas três primeiras peças, o paradigma flexional do verbo era constituído de seis oposições (às vezes cinco), ou seja, era formalmente "rico" (JAEGGLI e SAFIR 1989), o que garantiria a identificação do sujeito nulo. Por isso, observamos no gráfico a preferência pela não-expressão do sujeito, com percentuias acima de $75 \%$, mostrando que o PB se comportava como língua [+ pro drop].

Por outro lado, nas duas peças seguintes, a redução percentual de sujeitos nulos se relacionaria à neutralização das formas distintivas no paradigma flexional do verbo, promovida pela substituição dos pronomes tu e vós por você e vocês. Assim, o número de oposições teria passado de seis para quatro, dada a presença de dois sincretismos no paradigma: o morfema $\langle\emptyset\rangle$ tanto para a segunda, quanto para a terceira pessoa do singular, e o morfema $<-m>$ compartilhado pela segunda e terceira do plural. Com isso, a manutenção de quatro oposições no paradigma começa a mostrar os reflexos da erosão na morfologia verbal, o que denuncia o início do processo de mudança, com a segunda pessoa como a que revela os maiores índices de preenchimento. 
As peças correspondentes aos últimos 25 anos do séc. $\mathrm{XX}$ evidenciam que o comportamento do sujeito no PB, em relação ao séc. XIX, já não é mais o mesmo. A entrada da forma a gente em competição com o pronome nós, cada vez menos frequente na fala, teria feito com que fosse ultrapassado o limite de dois sincretismos estabelecidos por Duarte (1993) como máximo para que uma língua possa identificar/licenciar o sujeito nulo $^{2}$. Assim, o paradigma flexional do verbo no PB teria deixado de ser funcionalmente "rico", provocando, então, a preferência pela expressão do sujeito, como vemos nas duas últimas colunas do Grafico I, em que o percentual de sujeitos nulos é bastante baixo (33\% e $28 \%$ ).

\section{A MUDANÇA NO ESTATUTO CATEGORIAL DE HAVER: AVELAR (2006)}

Avelar (2006) analisa a questão da substituição de haver por ter no PB a partir da hipótese de uma mudança categorial do primeiro verbo. Dessa maneira, evidências empíricas mostram que haver teria passado de um verbo existencial funcional a um verbo existencial substantivo, ao contrário de ter, que se comporta como categoria funcional. $\mathrm{O}$ contraste entre ter e haver no trabalho de Avelar está baseado principalmente nos dados de Callou e Avelar (2000), sobre a fala culta carioca - do projeto NURC - nos anos 1970 e nos anos 1990. Das questões levantadas pelo autor, contemplo apenas três, que servirão de base para a análise que proponho mais adiante.

Para clarificar a ideia da mudança categorial de haver, é interessante recorrer a alguns pressupostos assumidos pela Morfologia Distribuída. Nessa perspectiva, em vez de um componente lexical, a gramática dos indivíduos conta com listas que abrigam informações sobre os itens lexicais. Assim, para uma dada derivação, é acessada uma primeira lista onde se agrupam tanto as categorias substantivas, representadas por substantivos, adjetivos e verbos plenos, como as categorias funcionais, que veiculam noções de tempo, modo, número e pessoa, desvinculadas de qualquer matriz fonológica. A derivação prossegue e uma segunda lista contendo as possibilidades materiais para as categorias funcionais que haviam entrado na derivação é acessada posteriormente, depois de SPELL-OUT. É nesse momento que as categorias funcionais são revestidas de material fonético, podendo ser aí interpretadas.

Segundo Avelar, tendo em conta as ideias de Embick e Noyer (2004), na segunda lista, que contém as entradas lexicais correspondentes às categorias funcionais constantes da primeira lista, também se encontram informações sobre as condições de realização das dadas matrizes fonológicas. Assim, de acordo com o Subset Principle ${ }^{3}$, se a certa

\footnotetext{
${ }^{2}$ Segundo a autora, na última peça foram encontradas ocorrências do pronome tu, mas com verbos já sem a marca de flexão $<-s>$.

3 “A matriz fonológica de um item vocabular é inserida numa determinada posição se o item reúne pelo menos uma parte dos traços que estão especificados em tal posição. A inserção deve ser bloqueada se o
}

Work. Pap. Linguíst., 15(1): 112-135, Florianópolis, jan/abr, 2014 
categoria funcional abstrata corresponde mais de uma matriz fonológica, aquela que vai se realizar será a que contiver o maior número de especificações adequadas às especificações referentes à posição em que se dará a inserção do item.

O primeiro indício da nova condição de haver é a diminuição da sua frequência de uso. Haver era o verbo prototipicamente existencial e perde espaço nesse contexto para ter. No Gráfico 2, podemos constatar a drástica queda do percentual de haver - sobretudo entre os mais jovens - quando se comparam os dois períodos de tempo contemplados no "estudo de tendência"4 (Cf. LABOV, 1994).

Gráfico 2: Distibuição de haver por três faixas etárias nas décadas de 1970 e 1990

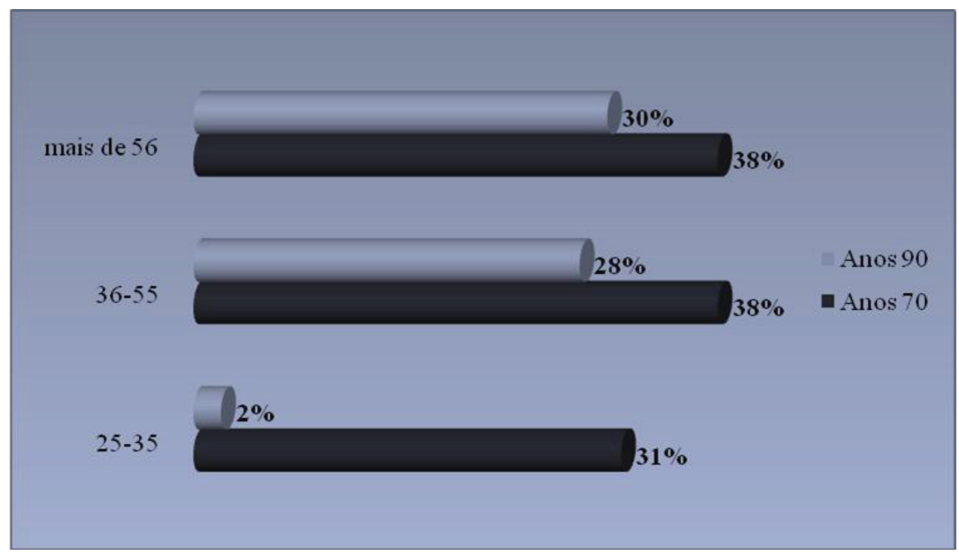

Fonte: Adaptado de Callou e Avelar (2000)

Nos dois períodos, os percentuais de ter são muito superiores aos de haver em todas as faixas etárias. É curioso notar que a diferença entre os anos 1970 e os anos 1990 no índice de uso de haver pela faixa mais baixa é muito significativa: primeiro, haver aparece com 31\%; posteriormente, seu uso corresponde a apenas $2 \%$, ilustrando a "mudança em tempo real de curta duração" da representação da existência no PB.

Avelar mostra ainda que, ao contrário de ter, haver não pode figurar, no PB atual, em qualquer sentença existencial. Há contextos em que a presença de haver torna a sentença existencial agramatical - ou pouco aceita -, o que não ocorre com ter, que sempre é possível em qualquer contexto existencial. Essa situação leva a crer que há condicionamentos específicos para a realização de haver, o que é explorado também por

item mostra informações (conjunto de traços e/ou condições de localidade para a inserção) que não condizem com a situação da categoria abstrata que deve receber a matriz. Quando vários itens reúnem condições para a inserção, aquele que reunir o maior número de informações correspondentes à categoria abstrata deve ser o escolhido." (AVELAR, 2006, p.52)

${ }^{4}$ Estudo de tendência investiga duas amostras de fala da mesma comunidade, estratificada segundo as mesmas variáveis sociais, colhidas no mesmo intervalo de tempo. 
Avelar. O autor, então, retorna aos dados de Callou e Avelar (2000) para mostrar dois aspectos linguísticos que atuam nesse sentido: o tempo verbal e o traço semântico do argumento interno.

Quanto ao tempo verbal, os resultados indicaram que o passado, de modo geral, parece condicionar a realização de haver em face de ter. Veja-se o Gráfico 3, que mostra os percentuais de haver nos dois períodos, distribuídos pelos tempos verbais.

Gráfico 3: Distribuição de haver pelos tempos verbais nas décadas de 70 e 90

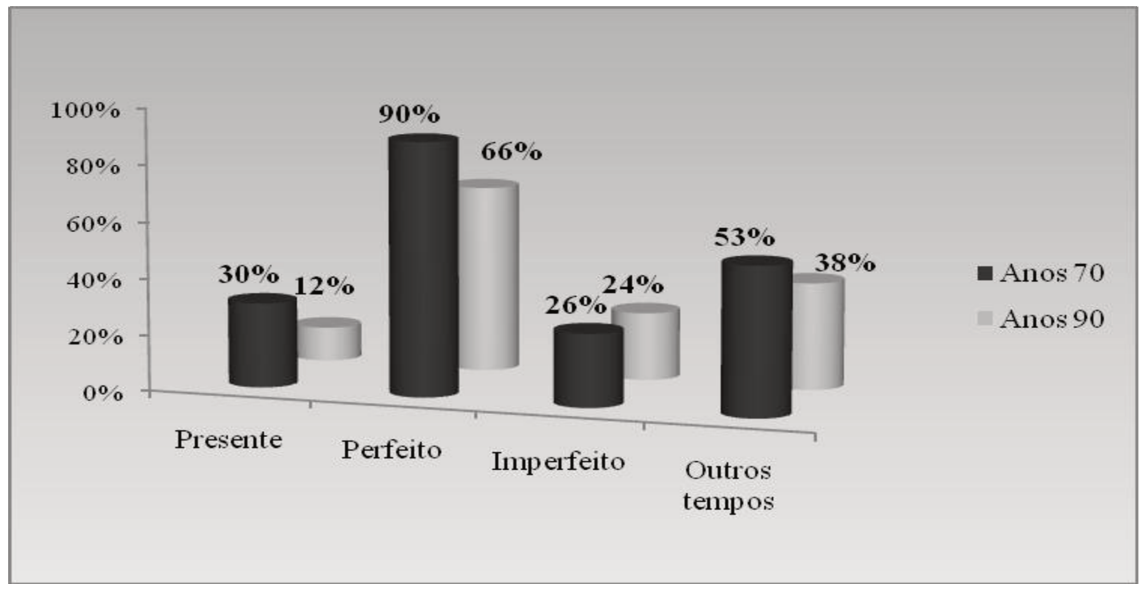

Fonte: CALLOU \& AVELAR, 2000

É curioso que, em ambos os períodos, é no passado que haver revela seus maiores índices, $90 \%$ em 1970 e $66 \%$ em 1990, ou seja, mais que a metade do quantitativo geral em cada período. Atribui-se esse resultado ao fato de que haver teria se tornado o verbo existencial prototípico da narrativa, tipo textual que favorece o uso do passado. Como se esperava, na condição de verbo existencial funcional, ter também encontra terreno no mesmo contexto, superando haver.

Sobre a questão do traço semântico do argumento interno, mais uma vez, ter revelou sua versatilidade, aparecendo associado a argumentos com qualquer traço: [+animado], [+material], [+abstrato], [+evento] e [+lugar], como se vê, respectivamente, ilustrados em (4), com exemplos retirados de Callou e Avelar (2000):

(4) a. aqui no Leblon tem o padre Zeca.

b. tinha biscoitos na Colombo.

c. não tem mais o charme que tinha.

d. quando eu fiz quinze anos, teve uma festa maravilhosa

e. tem bairros sensacionais fora de Salvador 
Por outro lado, haver parece ser favorecido pelos traços [-material], ou seja, [+abstrato] e [+evento], que apresentam percentuais de $50 \%$ e $41 \%$ no acumulado das duas décadas, em contraste com $17 \%$ do traço [+animado], $8 \%$, de [+inanimado] e $21 \%$ de [+espaço].

A análise separada da fala dos mais jovens também trouxe elementos importantes para a discussão sobre o estatuto do verbo haver no PB contemporâneo. Avelar constata que, nesse grupo, haver tem um comportamento ainda mais afastado de ter - e mais semelhante a existir - em termos de frequência: enquanto ter aparece com $75 \%$, existir exibe um índice de $4 \%$ e haver, $6 \%$. Os outros $15 \%$ correspondem às ocorrências de acontecer, outro verbo do tipo existencial substantivo.

Além disso, outro aspecto que chama a atenção é a completa ausência de haver no pretérito perfeito na fala dos mais jovens. Nesse contexto, foram encontradas apenas ocorrências de ter e acontecer. No imperfeito, por outro lado, as ocorrências ficam entre ter, haver e existir, mas nunca com acontecer, o que sugere que o tempo verbal condiciona o sentido assumido por haver: no pretérito perfeito, esse verbo é interpretado como acontecer; no imperfeito, como existir. Vê-se aqui outro argumento em favor da mudança no estatuto de haver, uma vez que há/havia e houve apresentam significados diferentes (entre os cariocas mais jovens). Isso parece apontar para o fato de que essas duas manifestações já não correspondem mais a matrizes diferentes de uma mesma categoria funcional. Ao contrário, as duas formas seriam listadas entre os itens substantivos, participando da derivação desde o início.

Levando em conta todas as análises realizadas por Avelar, o que, então, teria levado haver a perder o lugar para ter, especializando-se quanto ao uso e sofrendo a mudança de categoria apontada? Para responder essa pergunta, o autor lança mão de pressupostos da Morfologia Distribuída, ao afirmar que as matrizes ser, estar, ter e haver corresponderiam a uma categoria abstrata $v_{e s t}$ (AVELAR, 2004). Cada uma entraria na derivação de acordo com as condições especificadas pela entrada, de acordo com o Subset Principle. Assim, ter seria acionado quando a sentença se configurasse como possessiva e haver, quando se tratasse de uma configuração existencial. Indo mais além, Avelar apresenta uma hipótese para o surgimento de ter em contextos existenciais: haveria uma relação intrínseca entre as alterações no quadro pronominal, o enfraquecimento da concordância e a impossibilidade de licenciar/interpretar uma categoria vazia na posição de sujeito e a interpretação existencial de sentenças com ter e sujeito nulo. Assim, se é verdade que as alterações no quadro pronominal do PB levaram a uma redução no paradigma flexional do verbo, gerando a incapacidade de o sistema permitir que proref ocupasse a posição estrutural de sujeito, também é verdade que sentenças possessivas com ter e sujeito nulo não mais poderiam ser assim interpretadas, já que o falante fica impossibilitado de atribuir um valor referencial a essa posição. $\mathrm{O}$ que "salvaria" uma sentença assim seria interpretá-la como existencial, em que ter não tem sujeito gramatical, como ocorre com sentenças com haver. Estudos como os de Duarte (1993, 1995), Galves (1996), Tarallo (1996) mostram que esse conjunto de mudanças na 
marcação do PSN no PB parece ter se dado na passagem do séc. XIX para o séc. XX, momento em que se verifica a presença de ter nesses contextos.

Então, se ter com sujeito nulo passa a ser interpretado como existencial, o sistema teria passado a contar com duas matrizes fonológicas - ter e haver - para um mesmo conjunto de traços, o que impossibilitaria a aplicação do Subset Principle, uma vez que não seria possível eleger aquela mais adequada em dada condição. Além disso, haver teria que continuar se comportando da mesma maneira, como uma categoria funcional, o que não se verifica no PB atual. Parece que haver foi "expulso" do rol das categorias funcionais e passou a integrar as categorias substantivas, o que justifica sua frequência baixa - como ocorre com acontecer, existir e outros verbos da mesma natureza -, sua ausência na fala das crianças e a especialização do seu uso.

\section{OS DADOS}

\subsection{Metodologia de análise}

Para fornecer evidências empíricas sobre o fenômeno em estudo no presente trabalho, procedi a uma análise diacrônica, a partir do método quantitativo largamente usado nos estudos em Sociolinguística Variacionista, de sentenças existenciais em que aparecem os verbos haver, ter e existir em contexto em que há a possibilidade de ocorrência das três formas verbais ${ }^{5}$. Foram computados dados em que a alternância entre os verbos não implicaria mudanças significativas de sentido ou nas condições de valor de verdade das sentenças, conforme ilustrado em (5):

(5) Havia/Tinha/Existia um homem na esquina.

O corpus utilizado para a constituição da amostra de PB é um conjunto de 43 comédias teatrais - farsas, comédias de costumes, comédias de personagem, comédias de capa e espada, e comédias pastelão -, escritas entre 1844 e 1992, por autores cariocas ou que viveram no Rio de Janeiro durante a maior parte de suas vidas. As peças foram agrupadas em sete períodos, seguindo a mesma classificação adotada por Duarte (1993). Os dados do PE foram extraídos de 41 peças teatrais do mesmo gênero, igualmente agrupadas, respeitando a divisão estabelecida para o $\mathrm{PB}$.

\footnotetext{
${ }^{5}$ Evidentemente é necessário observar que a mudança na forma verbal acarretará mudanças do ponto de vista semântico, sobretudo se se considerar, assim como defendo neste ponto, que as três matrizes não correspondem ao mesmo tipo de categoria - ter é uma categoria funcional, enquanto haver e existir são categorias substantivas - e não codificam o mesmo conjunto de traços. Entretanto, para obter dados que permitam a análise, foi necessário desconsiderar tal distinção e selecionar as sentenças em que a entrada dessa ou daquela forma verbal não gerasse a agramaticalidade da sentença e que produzisse um sentido mais aproximado ao da "posse pura", que assumo ser aquela veiculada pelo verbo existir.
}

Work. Pap. Linguíst., 15(1): 112-135, Florianópolis, jan/abr, 2014 
Para o processamento quantitativo dos dados de $\mathrm{PB}$, foi utilizado o pacote de programas VARBRUL (PINTZUK, 1988), que permitiu não só determinar as frequências de uso das variantes em questão em cada período de tempo, como também os fatores que parecem ter entrado em jogo no processo de alternância entre as duas formas - e posterior sobreposição de uma forma pela outra - no curso do tempo. Como meu objetivo neste ponto é verificar se a hipótese de Avelar (2006) se aplica aos dados que coletei, estes foram codificados de acordo com os mesmos grupos de fatores indicados em Callou e Avelar (2000), a saber:
(a) elemento à esquerda do verbo
(b) tempo verbal
(c) posição do argumento interno
(d) traço semântico do argumento interno
(e) tipo sintático da oração
(f) período de tempo.

\subsection{Análise dos dados}

\subsubsection{Resultados gerais do PB}

$\mathrm{Na}$ amostra de peças brasileiras, foram computadas 986 sentenças, das quais 649 exibiam o verbo haver, 290, o verbo ter e apenas 47, o verbo existir. O Gráfico 4 e a Tabela 1 a seguir mostram a distribuição dos usos dos três verbos ao longo do tempo.

Gráfico 4: Distribuição de haver, ter e existir ao longo dos sete períodos de tempo (PB)

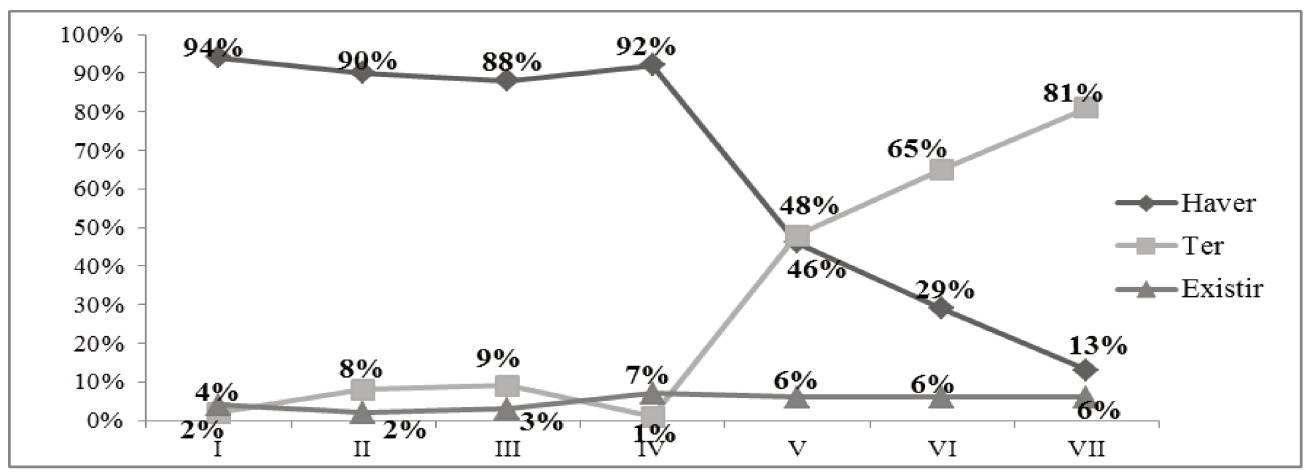

Tabela 1: Distribuição de haver, ter e existir ao longo dos sete períodos de tempo (PB)

\begin{tabular}{|l|l|l|l|}
\hline \multicolumn{2}{l}{ Período } & \multicolumn{1}{l}{ Taver } & Existir \\
\hline I (1840 - 1860) & $147-94 \%$ & $4-2 \%$ & $6-4 \%$ \\
\hline II $(1870-1889)$ & $114-90 \%$ & $10-2 \%$ & $3-2 \%$ \\
\hline
\end{tabular}




\begin{tabular}{|l|l|l|l|} 
III (1899 - 1920) & $123-88 \%$ & $12-9 \%$ & $4-3 \%$ \\
\hline IV (1933 - 1945) & $\mathbf{1 1 4 - 9 2 \%}$ & $\mathbf{1 ~ - ~ 1 \%}$ & $\mathbf{9 - 7 \%}$ \\
\hline V $(1953-1967)$ & $99-46 \%$ & $104-48 \%$ & $12-6 \%$ \\
\hline VI $(1975-1984)$ & $41-29 \%$ & $90-65 \%$ & $8-6 \%$ \\
\hline VII $(1990-20 \ldots)$ & $11-13 \%$ & $69-81 \%$ & $5-6 \%$ \\
\hline Total (ocor.) & $\mathbf{6 4 9}$ & $\mathbf{2 9 0}$ & $\mathbf{4 7}$
\end{tabular}

Como se vê, conforme esperado, as frequências de uso de haver, nos quatro primeiros períodos, ou seja, até os anos 30 do século $\mathrm{XX}$, revelam índices bastantes altos, acima da casa dos $90 \%$, enquanto os períodos V, VI e VII, que compreendem peças escritas a partir dos anos 1950, mostram o declínio dessa forma. Em situação diametralmente oposta, encontramos o verbo ter, que apresenta inexpressivos índices de ocorrência nos períodos I, II, III e IV, não atingindo sequer a marca de $10 \%$. É no período V que se observa a competição equilibrada entre as duas formas, e, a partir de então, ter ultrapassa o uso de haver, chegando a $81 \%$ no último período. Esses resultados preliminares já evidenciam uma mudança no comportamento dos verbos haver e ter nos contextos existenciais. Se num primeiro momento os números indicam que haver era o verbo existencial prototípico - quando se observa sua frequência - e ter exibia um comportamento mais marginal nesse contexto, a situação a partir dos anos 1970 (período VI) se inverte: ter passa a representar a noção de existência numa proporção muito maior que haver, que passa a apresentar uma frequência de uso semelhante à de existir, que manteve padrões razoavelmente constantes, com percentuais que não chegam a $10 \%$.

O Gráfico 5 a seguir traça um paralelo entre os resultados apresentados anteriormente e aqueles encontrados por Duarte (1993), para a representação do sujeito pronominal.

Gráfico 5: Distribuição de ter vs. crescimento de sujeitos de referência definida plenos ao longo dos 7 períodos de tempo $(\mathrm{PB})$

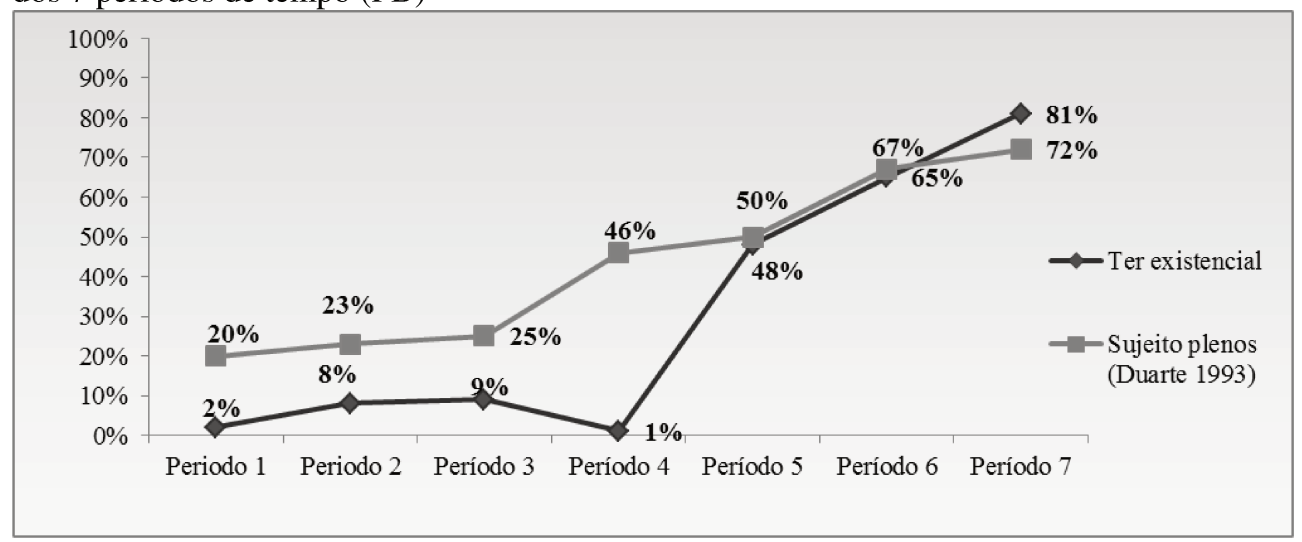


Observe-se que as curvas ascendentes para a implementação de ter existencial e do sujeito pronominal expresso seguem paralelas, sempre com o preenchimento do sujeito ocorrendo mais rapidamente do que o uso de ter. Percebe-se uma situação de proximidade entre a presença de ter existencial e sujeitos plenos nos três primeiros períodos: os percentuais de sujeitos plenos ainda são muito baixos, entre $20 \%$ e $25 \%$, do mesmo modo que os índices de ter existencial, que ficam entre $2 \%$ e $9 \%$. Isso denota duas situações: por um lado, a baixa frequência de sujeitos plenos mostra que o sistema ainda tem a capacidade de licenciar/interpretar a categoria vazia na posição estrutural de sujeito. Isso possibilita que sentenças com ter e sujeito nulo ainda sejam interpretadas como possessivas. Contudo, é possível que, em algum ponto do séc. XIX, o PB tenha começado a apresentar um comportamento diferente em relação à marcação do PSN. Como consequência, as sentenças com ter e sujeito nulo, cada vez mais, vêm deixando de poder ser interpretadas como possessivas, restando a elas a semântica existencial. Levando-se em consideração que o período III vai até 1920 e, mais ainda, que os autores dos três primeiros períodos nasceram até meados do séc. XIX, é bastante aceitável pensar que as peças desses três períodos ainda reflitam aspectos de gramáticas de sincronias anteriores. E ainda, é muito provável que, nesse momento histórico, os indivíduos mais velhos sejam portadores de gramáticas em que a categoria vazia que ocupa a posição estrutural de sujeito ainda pode ser interpretada - e que, portanto, atribuem valor possessivo à combinação ter + sujeito nulo, e os indivíduos mais jovens já não consigam fazer o mesmo. Para eles, assim, essa combinação resultaria em uma sentença existencial.

Deve-se notar, porém, a situação encontrada no quarto período, em que há uma ruptura em relação aos demais índices de aparecimento de ter existencial. Os três autores das peças de onde foram extraídos os dados do período se mostram, de fato, mais conservadores com relação ao uso de ter existencial, diferentemente do que se esperaria. Note-se que um deles, autor muito popular em seu tempo - Armando Gonzaga - é apontado por Duarte (1993) como o autor que opta pelo uso de você, abandonando o pronome $t u$ em suas peças. Isso, segundo a autora, seria um dos elementos favorecedores do preenchimento do sujeito. Por outro lado, em outros estudos relacionados aos efeitos da mudança na remarcação do PSN, são os autores desse período que apresentam um desvio nas curvas de mudança (Cf. Duarte 2012, sobre diversos estudos diacrônicos com base no mesmo conjunto de peças). Não há dúvida de que estamos num período em que a pressão normativa se torna mais forte e atua de maneira mais eficiente em relação ao uso de haver do que em relação ao uso de um pronome sujeito nulo.

Passo, então, a fazer algumas considerações sobre as ocorrências com existir. $\mathrm{Na}$ qualidade de verbo existencial substantivo, era esperada uma frequência mais ou menos constante em todos os períodos. Além disso, o baixo número de ocorrências - no total 47 - indica que o uso de existir é mais restrito, possivelmente por conta de seu conjunto de traços semânticos, ligados à ideia de um valor existencial "mais neutro", que defino aqui 
como "ter existência real, ser real, estar no/pertencer ao mundo biossocial compartilhado"6.

\subsubsection{Contextos linguísticos no PB}

Os resultados preliminares foram capazes de mostrar que, em termos de frequência de uso, ter toma o lugar de haver nas sentenças existenciais e que haver passa a figurar com índices mais próximos dos verbos existenciais substantivos, como é o caso de existir. A seguir, tratarei dos contextos que me pareceram mais relevantes, sobretudo levando em conta as afirmações de Avelar (2006).

\subsubsection{O tempo verbal}

O objetivo da análise a ser apresentada é de verificar se a hipótese de Callou e Avelar (2000), de que o tempo verbal que favoreceria o uso de haver é o pretérito perfeito, ideia que serve de base para a tese de que haver teria se especializado no discurso narrativo (CALLOU e AVELAR 2000; AVELAR 2006). Apresento a análise desse grupo de fatores nos três últimos períodos, momento em que ter passa a suplantar haver em termos de frequência de uso. Como se viu, até o período IV, haver exibia comportamento de categoria funcional, o que pressupõe um comportamento uniforme no que se refere ao tempo verbal e justifica uma análise daí em diante.

Observando todos os dados, tanto de ter, quanto de haver, e considerando o quantitativo geral dos três períodos, o presente é o tempo verbal que concentra o maior número de dados. A Tabela 2 mostra os resultados encontrados para haver, considerando cada período separadamente.

Tabela 2: Distribuição de haver pelos tempos verbais a partir da segunda metade do séc. XX (PB)

\begin{tabular}{|l|l|l|l|l|}
\hline Tempo/Período & Período V & Período VI & Período VII & Total \\
\hline Presente & $63-64 \%$ & $25-61 \%$ & $7-64 \%$ & $95-63 \%$ \\
\hline Perfeito & $11-11 \%$ & $7-17 \%$ & $1-9 \%$ & $19-12,5 \%$ \\
\hline Imperfeito & $13-13 \%$ & $6-15 \%$ & $*$ & $19-12,5 \%$ \\
\hline Outros & $12-12 \%$ & $3-7 \%$ & $3-27 \%$ & $18-12 \%$ \\
\hline Total & $\mathbf{9 9 - 1 0 0 \%}$ & $\mathbf{4 1 - 1 0 0 \%}$ & $\mathbf{1 1 - 1 0 0 \%}$ & $\mathbf{1 5 1 - 1 0 0 \%}$ \\
\hline
\end{tabular}

\footnotetext{
${ }^{6}$ Está fora do escopo deste artigo definir com precisão o significado de existência ou do que é ou não real, independentemente de qualquer corrente filosófica.
} 
O que se pode notar através da leitura da Tabela 2 é que os percentuais de haver no presente são muito semelhantes, na casa dos 60\%. Esses percentuais, entretanto, não podem ser tomados como indicativos de que o tempo presente seja um fator condicionante para a manutenção de haver no sistema do PB. Índices muito semelhantes foram encontrados para ter, como se vê na Tabela 3.

Tabela 3: Distribuição de ter pelos tempos verbais nos a partir da segunda metade do séc. XX (PB)

\begin{tabular}{|l|l|l|l|l|}
\hline Tempo/Período & Período V & Período VI & Período VII & Total \\
\hline Presente & $87-84 \%$ & $61-68 \%$ & $59-85 \%$ & $207-79 \%$ \\
\hline Perfeito & $4-4 \%$ & $5-6 \%$ & $*$ & $9-3 \%$ \\
\hline Imperfeito & $8-7 \%$ & $22-24 \%$ & $3-5 \%$ & $33-13 \%$ \\
\hline Outros & $5-5 \%$ & $2-2 \%$ & $7-10 \%$ & $14-5 \%$ \\
\hline Total & $\mathbf{1 0 4 - 1 0 0 \%}$ & $\mathbf{9 0 - 1 0 0 \%}$ & $\mathbf{6 9 - 1 0 0 \%}$ & $\mathbf{2 6 3 - 1 0 0 \%}$ \\
\hline
\end{tabular}

Como se pode notar, as tabelas parecem indicar que é também no presente que as ocorrências de ter são mais numerosas, uma vez que chegam a $85 \%$ no último período. A situação retratada pelas duas tabelas anteriores, não parece, entretanto, indicar que o tempo presente favoreça uma das formas verbais existenciais, embora essas sentenças configurem-se como as que apresentam maiores índices. Na verdade, sentenças no presente, sejam elas existenciais ou não, serão de fato mais recorrentes no gênero textual em questão, no caso peças teatrais, em que as falas e as ações ocorrem simultaneamente.

Entretanto, ao se comparar as ocorrências de ter com aquelas de haver, é possível verificar um aspecto que não fica nítido pela observação das duas tabelas. Veja-se o Gráfico 6 a seguir.

Gráfico 6: Distribuição de ter e haver pelos tempos verbais nos três últimos períodos (PB) 


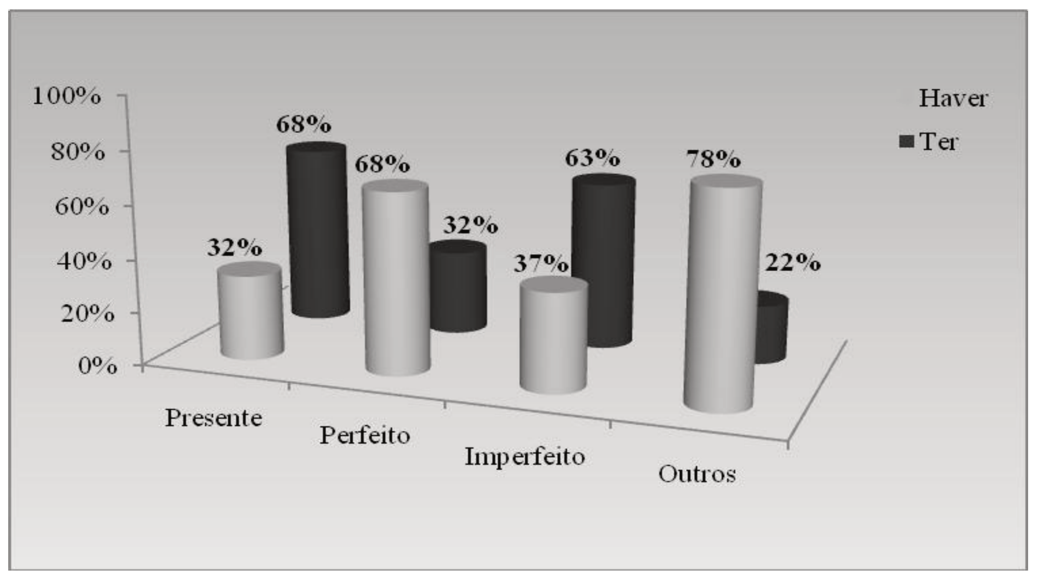

A distribuição que se encontra quando comparados os números de ter e haver, conforme mostra o Gráfico 6, é semelhante ao que Callou e Avelar (2000) encontram para a fala culta carioca. Aqui se pode notar que o percentual de haver no pretérito perfeito é bastante superior ao de ter, chegando a $68 \%$ contra $32 \%$, faixa semelhante àquela encontrada pelos autores. Por outro lado, no presente e no pretérito imperfeito, ter suplanta haver, também com percentuais da mesma ordem de grandeza em relação aos dados de Callou e Avelar (2000).

Visto isso, os dados permitem compreender que, embora o tipo de texto usado para constituir a amostra não privilegie o aparecimento de sequências narrativas, como é o caso do tipo de inquérito que serviu de base para a análise de Callou e Avelar (2000), quando isso ocorre, os maiores percentuais são os de haver. Isso parece sugerir que, de algum modo, haver estaria associado ao discurso narrativo, encontrando assim, um ambiente discursivo de resistência, especializado nesse uso.

\subsubsection{Traço semântico do argumento interno}

Segundo mostram Callou e Avelar (2000), haver aparece mais comumente associado aos traços semânticos "não materiais", como é o caso do traço [+abstrato] e [+evento]. Na medida em que vai deixando de ser um verbo existencial funcional, haver vai deixando de aparecer nos contextos em que seu argumento interno exibe um conteúdo nocional concreto, como é o caso do traço [+animado], [+material] e [+espaço].

Assim, ter deveria ter encontrado nesses ambientes linguísticos um terreno fértil para a sua implementação, espraiando-se para os outros contextos na medida em que se torna o verbo existencial. Com isso, espera-se, de acordo com os resultados apresentados até aqui, que isso tenha acontecido a partir da segunda metade do séc. XX, que corresponde ao quinto período. 
Seguindo as diretrizes metodológicas estabelecidas em Callou e Avelar (2000), analiso as ocorrências de ter nos três primeiros períodos e haver nos três últimos, quanto ao traço semântico de seu argumento interno. O conteúdo semântico dos argumentos internos dos verbos foi classificado como [+animado], [+material], [+abstrato], [+evento] e [+lugar]. Observem-se as tabelas 4 e 5 a seguir.

Tabela 4: Traço semântico do argumento interno através dos três últimos períodos - verbo haver (PB)

\begin{tabular}{|l|l|l|l|} 
Traço semântico & V & VI & VII \\
\hline [+animado] & $22-22 \%$ & $5-12 \%$ & $3-27 \%$ \\
\hline [+material] & $10-10 \%$ & $2-5 \%$ & $2-18 \%$ \\
\hline [+abstrato] & $61-62 \%$ & $26-63 \%$ & $6-55 \%$ \\
\hline [+evento] & $4-4 \%$ & $6-15 \%$ & - \\
\hline [+lugar] & $2-2 \%$ & $2-5 \%$ & - \\
\hline Total & $99-100 \%$ & $41-100 \%$ & $11-100 \%$
\end{tabular}

Tabela 5: Traço semântico do argumento interno através dos três últimos períodos - verbo ter (PB)

\begin{tabular}{|l|l|l|l|}
\hline Traço semântico & I & $3-30 \%$ & $2-17 \%$ \\
\hline [+animado] & $3-75 \%$ & $3-30 \%$ & $3-25 \%$ \\
\hline [+material] & - & $4-40 \%$ & $5-41 \%$ \\
\hline [+abstrato] & $1-25 \%$ & - & - \\
\hline [+evento] & - & - & $2-17 \%$ \\
\hline [+lugar] & - & $10-100 \%$ & $12-100 \%$ \\
\hline Total & $4-100 \%$ & &
\end{tabular}

A análise da Tabela 4 permite notar que em todos os três períodos o traço [+abstrato], exemplificado em (6), aparece com os maiores percentuais, tendo alcançado índices na casa dos $60 \%$ nos períodos V e VI e $55 \%$ no período VII.

(6) Há diferenca de cromossomos. (A Mulher Integral, Carlos Eduardo Novaes, 1975)

Se somado com o traço [+evento], ilustrado em (7), que também se caracteriza como abstrato, os números são ainda maiores: $66 \%$ no período $\mathrm{V}$ e $78 \%$ no período VI. Como no sétimo período não foram encontrados dados de argumento interno com o traço [+evento], o número se mantém o mesmo.

(7) No entanto, nunca houve tanto divórcio, tanta separacão como agora. (A Mulher Integral, Carlos Eduardo Novaes, 1975) 
Assim, em nenhum dos três períodos, argumentos com os traços ligados a uma noção material - [+animado], ilustrado em (8), [+material], em (9), [+lugar], em (10) - superam em número os argumentos internos com os traços abstratos.

(8) Nesta cidade não há um cristão que jogue xadrez? (O santo milagroso, Lauro Cesar Muniz, 1963)

(9) Você nasceu com as costas pra lua, hein? É apanhado, e o guarda sumiu. Chamo a polícia, polícia não vem. Não há táxi. E agora ainda me chamam com urgência. (Do tamanho de um defunto, Millor Fernandes, 1955)

(10) Mesmo porque meu irmão não vai ter a mesma sorte que teve meu pai, que entrou aí nessa baiuca e nunca mais saiu. E naquele tempo não havia boite! (O colar de coral, Antonio Callado, 1953)

Esse resultado confirma o que foi observado por Callou e Avelar (2000) para a fala culta, e colabora para reforçar a ideia de que o traço semântico [+abstrato] seria um contexto de resistência de haver.

Observando a Tabela 5, é possível notar que a situação prevista no início desta seção se confirma: ter parece mesmo se implementar no lugar de haver nos contextos em que este verbo vai desaparecendo, com argumentos internos portadores dos traço semânticos ligados à noção material. No período I, em que foram encontradas apenas 4 ocorrências de ter existencial, três delas estão associadas a um argumento interno com o traço [+animado]. A situação que se observa nos dois outros períodos é interessante: conforme se implementa no sistema nas construções existenciais, ter passa a invadir todos os contextos, independentemente do traço de seu argumento interno, processo sugerido pela Tabela 5: a distância entre os índices de argumentos com traços do tipo material em oposição aos com traços do tipo abstrato vai diminuindo com o passar do tempo, gerando o equilíbrio que se verifica no período III, quando se compara, de um lado, os traços [+animado], ilustrado em (11), [+material], ilustrado em (12), e [+lugar], ilustrado em (13).

(11) Tem uma amiga minha que disse que vai me arrumar preu ser revendedora da Avon (No coração do Brasil, Miguel Falabella, 1992)

(12) É. Mas durante a noite refresca um pouco mais, porque tem água em abundância. (Um elefante no caos, Millôr Fernandes, 1955)

(13) E tem o quarto da empregada, lá fora. (Um elefante no caos, Millôr Fernandes, 1955) 
Se por um lado, ao longo do processo de implementação de ter existencial no sistema do PB, o traço semântico do argumento interno pode ter sido relevante, com os traços materiais atuando a favor da introdução dessa forma verbal nos contextos existenciais, o panorama sugerido pelos resultados expostos na Tabela 5 - em que se analisam os períodos mais atuais - é o de um sistema em que ter aparece em qualquer contexto, sem que haja qualquer atuação do traço semântico do argumento interno, mostrando que tal forma verbal se encontra implementada no sistema. Observe-se o Gráfico 7 a seguir, em que se verifica a distribuição de ter de acordo com o traço semântico do argumento interno no período VII.

Gráfico 7: Distribuição de ter pelo traço semântico do seu argumento interno - Período VII (PB)

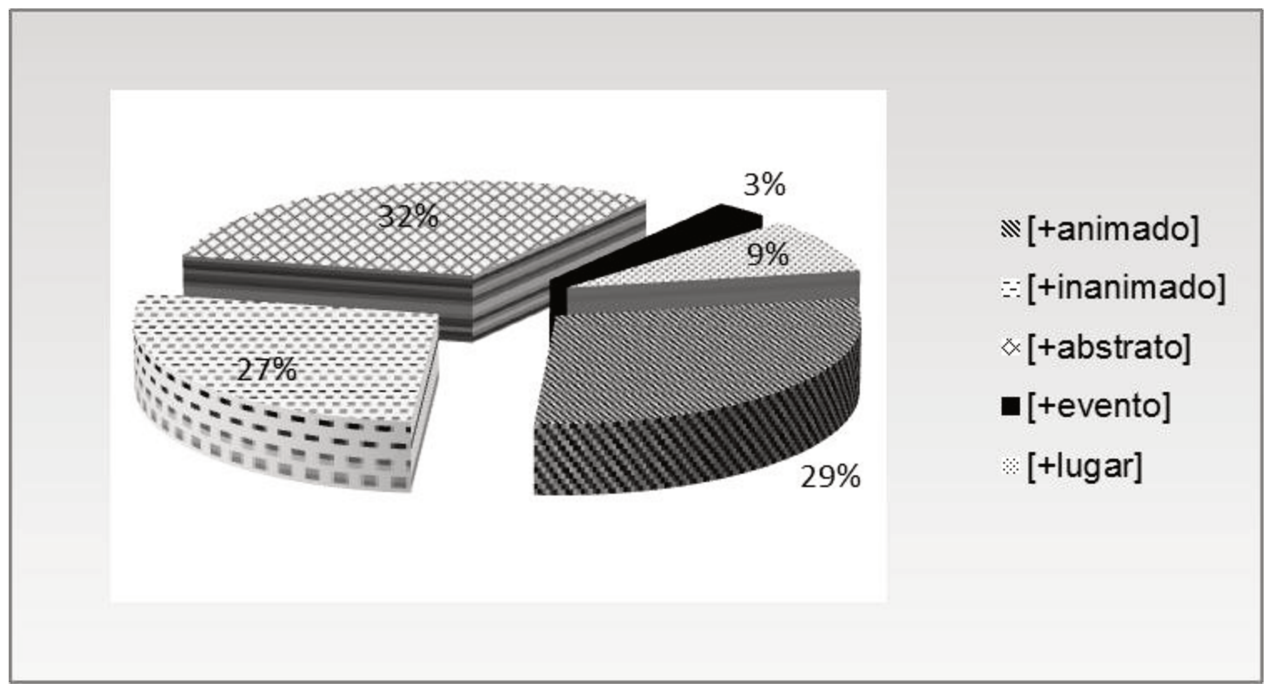

A distribuição de ter no último período, quando já se encontra totalmente implementado no sistema como verbo existencial, é bem mais uniforme. Pode-se observar que, quanto aos três traços principais, [+animado], [+inanimado] e [+abstrato], os percentuais são quase os mesmos, entre $27 \%$ e $32 \%$. A escassez de dados de argumentos internos com os traços [+evento] e [+lugar] não compromete os resultados: se unidos, respectivamente aos traços [+abstrato] e [+inanimado], vão compor percentuais de $35 \%$ e $36 \%$, o que torna os resultados ainda mais equilibrados, evidenciando o caráter uniforme do comportamento de ter no PB contemporâneo no que se refere ao traço semântico do seu argumento interno.

\subsubsection{Os dados do PE}

No que se refere à representação da noção de existência no $\mathrm{PE}$, a expectativa era que o haver apresentasse um comportamento de verbo funcional, figurando como o verbo existencial prototípico. Por essa razão, esperava-se que os percentuais de haver fossem os mais elevados e que seu uso estivesse associado aos mais variados contextos linguísticos 
e discursivos, semelhantemente ao comportamento que o verbo ter exibe hoje no PB. Por outro lado, atentando para os resultados de Eleutério (2003), que observou a presença de ter existencial numa amostra do $\mathrm{PE}$, ainda que numa proporção pequena em relação a haver, e de Bazenga (2012), que realiza uma análise de uma amostra do PE da Ilha da Madeira e encontra também dados de ter existencial nesta variedade, seria possível encontrar sentenças existenciais com o verbo ter na amostra em análise. No que se refere a existir, esperava-se encontrar percentuais baixos e usos condicionados pelo ambiente discursivo, comportamento característico de verbos substantivos, como mostrei na análise geral do PB.

Desse modo, foram encontrados 747 dados na amostra de PE, dos quais 709 constituíam sentenças com haver e 38 com existir. A distribuição percentual por período se encontra no Gráfico 8 a seguir.

Gráfico 8: Distribuição das sentenças existenciais no PE ao longo dos sete períodos de tempo

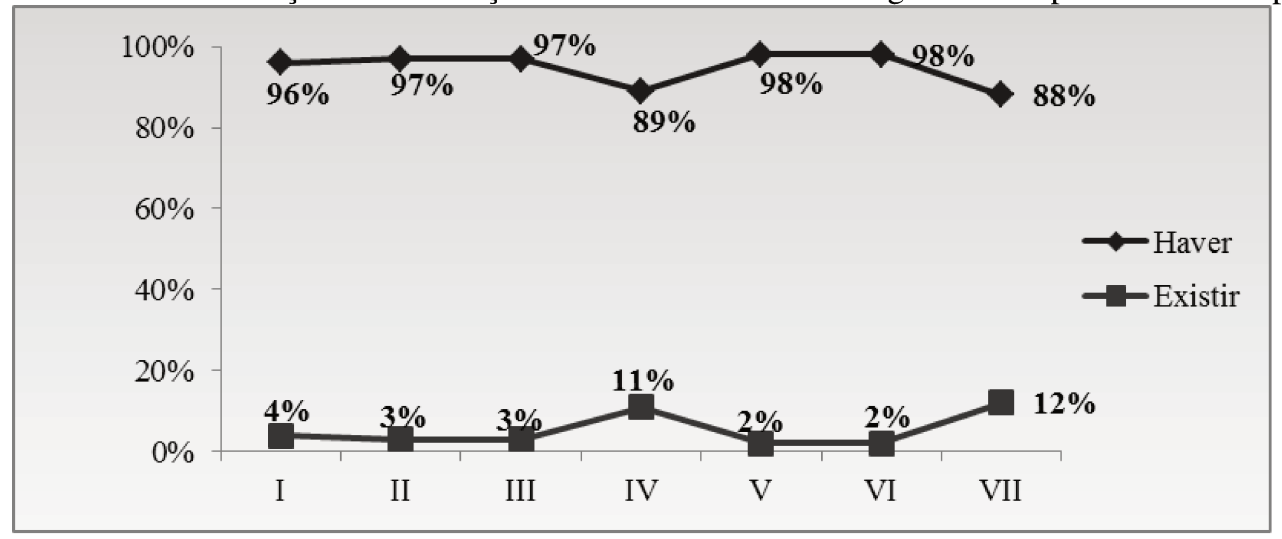

Conforme o Gráfico 8, o verbo haver no $\mathrm{PE}$, atendendo às expectativas, é o verbo existencial prototípico, figurando em todos os períodos não só com percentuais muito mais elevados do que os encontrados no PB contemporâneo, mas igualmente com distribuição regular ao longo do tempo. Esse resultado deixa mais nítida a mudança ocorrida no PB, quando comparadas as duas variedades. A observação do Gráfico 9 a seguir permite notar que, se nos primeiros períodos os percentuais de uso de haver eram semelhantes no PE e no PB, em torno dos $90 \%$, nos três últimos é possível notar uma distância cada vez maior, com o PE mantendo índices muito elevados de haver - 98\% nos períodos V e VI, e $88 \%$ no período VII -, enquanto no PB as taxas caem significativamente, chegando a $13 \%$ no último período.

Gráfico 9: Distribuição de haver nas duas variedades do português 


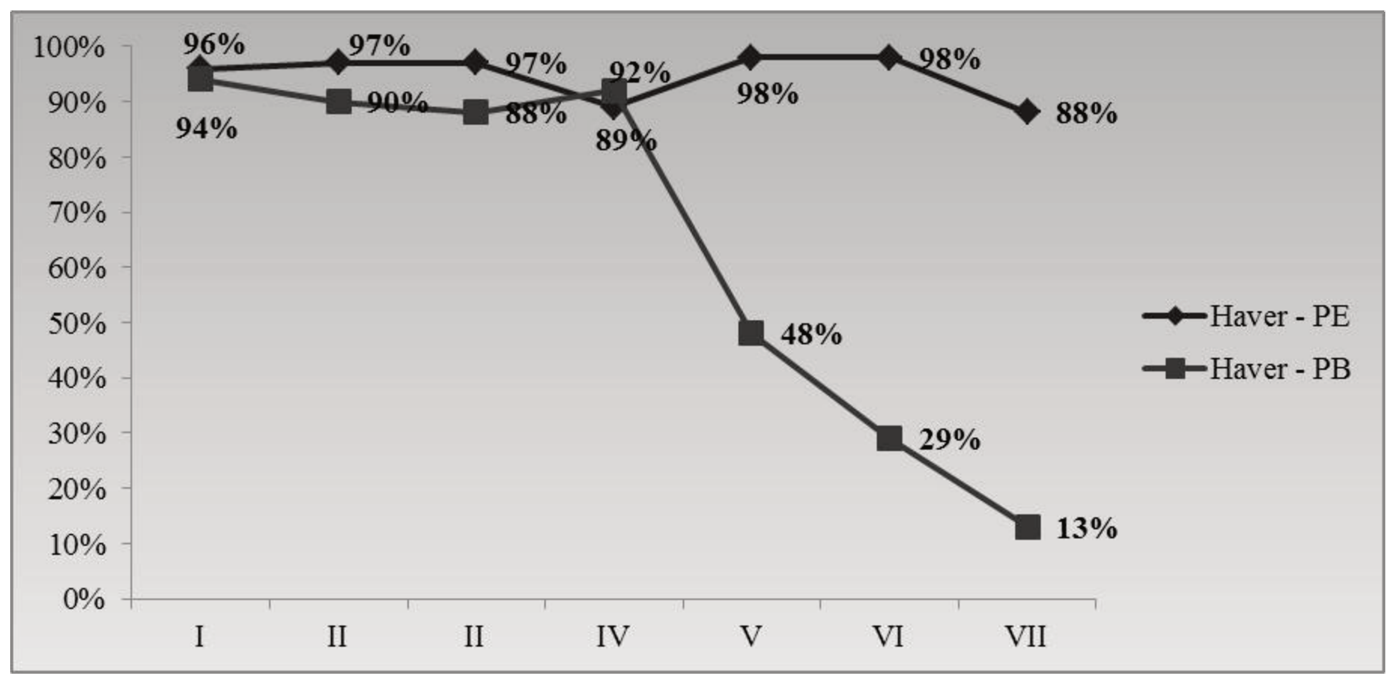

Não foram encontrados dados de ter existencial na amostra em análise, o que, conjugado à situação descrita anteriormente, sugere que a gramática utilizada para a representação da fala de personagens contemporâneos ao momento em que as peças foram escritas não parece contar com o verbo ter para a expressão da noção de existência. Assim, de um lado, o PE conta com haver como verbo existencial funcional, compondo a lista das categorias funcionais. De outro lado, outros verbos, como existir e acontecer, assim como no PB, integram a lista de categorias substantivas, exercendo o papel de verbos existenciais/apresentacionais substantivos. Considerando os resultados de trabalhos como os de Bazenga (2012) e Carrilho (2009), a presença de ter existencial no PE parece estar restrita às variedades tidas pelos portugueses como "não-padrão" ou dialetais, como preferem alguns autores, e aparece no sistema de forma marginal.

\section{CONSIDERAÇÕES FINAIS}

$\mathrm{Na}$ tentativa de esboçar uma possível trajetória da mudança ocorrida no PB na representação das sentenças existenciais, observei aspectos do comportamento de haver, ter e existir no curso do tempo, ao longo dos séculos XIX e XX. Como se viu, haver parece de fato ter passado por uma mudança em seu estatuto categorial, deixando de integrar a lista dos itens funcionais e passando a se comportar como uma categoria substantiva, tal qual existir. No caso de haver, além da questão do traço semântico [+abstrato] do seu argumento interno, essa é uma forma que parece ter se especializado no discurso narrativo, sendo mais recorrente no pretérito. Como consequência disso, ter e haver não seriam mais formas variantes e se mantêm no PB como categorias diferentes: o primeiro é uma categoria funcional, atuando como verbo existencial canônico, e o segundo integra a categoria de verbo substantivo ao lado de existir, acontecer, por exemplo. 
Os dados ainda revelaram que as alterações no quadro pronominal, o consequente enfraquecimento da morfologia verbal e a perda da possibilidade de licenciar pro $_{\text {ref }}$ na posição de sujeito de ter possessivo teriam sido responsáveis pela entrada desse verbo nas construções existenciais. Esse quadro ilustra a relação entre as mudanças sofridas pelas sentenças existenciais e a remarcação do PSN no PB.

Em outro extremo, o PE, que não apresentou qualquer ocorrência de ter existencial, mostrou um comportamento semelhante ao que se encontrou para o PB nos primeiros períodos, mas do qual o $\mathrm{PB}$ acabou por se afastar: haver como prototípico verbo existencial e existir, com índices baixos e regulares em todos os períodos.

Os fatos apresentados neste trabalho colaboram para reforçar a distância entre as duas variedades do português quanto à representação do sujeito pronominal e à representação da existência, o que parece reforçar a ideia defendida por muitos de que estamos diante de duas gramáticas distintas. Fica claro que a representação da existência não se limita a aspectos apenas lexicais: a reestruturação do sistema frente à mudança na marcação paramétrica parece ter como consequência o quadro esboçado aqui, evidenciando o "encaixamento" da mudança.

\section{REFERÊNCIAS}

AVELAR, J. O. Dinâmicas morfossintáticas com ter, ser e estar em português brasileiro. Dissertação de Mestrado. Campinas: Unicamp, 2004.

De verbo funcional a verbo substantivo: uma hipótese para a supressão de HAVER no português brasileiro. Letras de Hoje, Porto Alegre: PUC-RS, v. 143, 2006, p. 49-74.

\& CALLOU, D. Sentenças existenciais e preenchimento de sujeito: indícios de mudança em progresso na fala culta carioca. In: SILVA, A.; TORRES, A.; GONÇALVES, M. (Org.). Línguas Pluricêntricas - Variação Linguística e Dimensões Sociocognitivas. Braga: Aletheia, 2011, p. 287-300.

CARRILHO, E. Expletive ele in European Portuguese Dialects. Tese de Doutoramento. Lisboa: Universidade de Lisboa, 2005.

Sobre o expletivo ele em português europeu. In: Estudos de linguística galega, 2009. p. 7-26.

BAZENGA, A. Non-dominant TER (to have) - Existential in Spoken EP of Funchal (Madeira Island). In: II International Conference on Non-Dominant Varieties of Pluricentric Languages, 2012, Salamanca.

CALLOU, D. \& AVELAR, J. O. Sobre ter e haver em construções existenciais: variação e mudança no português do Brasil. Gragoatá 9, 2000. p. 85-100

\& AVELAR, J. O. Estruturas com ter e haver em anúncios do século XIX. In: ALKMIM, T. (org.). Para a história do português brasileiro. Vol. III. São Paulo, Humanitas/USP, 2002. p. 47-67 
CHOMSKY, N. On Phases. In. FREIDIN, R.; OTERO, C. P. \& ZUBIZARRETA, M. L. (orgs.) Foundational Issues in Linguistic Theory. Cambridge, MA: MIT Press, 2008. p. 133-166.

Minimalist inquiries: The framework. MIT Occasional Papers in Linguistics 15, 2001. p.01-61.

. The minimalist program. Cambridge, MA: The MIT Press, 1995.

COELHO, I. L. A ordem V DP em construções monoargumentais: uma restrição sintático-semântica. Tese de Doutorament. Florianópolis: UFSC, 2000.

CYRINO, S.; DUARTE, M. E. L. \& KATO, M. Visible subjects and invisible clitics in Brazilian Portuguese. In: KATO, M. \& NEGRÃO, E. (orgs.). Brazilian Portuguese and the Null Subject. Frankfurt am Main: Vervuert Verlag, 2000. p. 55-74.

DUARTE, M. E. L. Do pronome nulo ao pronome pleno: a trajetória do sujeito no português do Brasil. In: ROBERTS, I. \& KATO M. (Org.) Português Brasileiro: uma viagem diacrônica. Campinas: Editora. da UNICAMP, 1993. p. 107-128.

A perda do princípio "Evite Pronome" no português brasileiro. Tese de Doutoramento. Campinas: IEL/Unicamp, 1995.

. Sobre outros frutos de um projeto herético: o sujeito expletivo e as construções de alçamento. In: CASTILHO, A. et al. (Org.) Descrição, história e aquisição do português brasileiro. Campinas: Pontes, 2007.p. 35-48.

O sujeito em peças de teatro (1833-1992) Estudos Diacrônicos. São Paulo: Parábola, 2012.

\& MARINS, J. Uma análise comparativa das construções de indeterminação na fala e na escrita. In Cadernos do CNLF, v. IX, $\mathrm{n}^{\circ}$ 15. Disponível em: http://www.filologia.org.br/ixcnlf/15/19.htm.

.; MARTINS, A. M. \& NUNES, J. Controle e Alçamento/Elevacão em Português: Aspectos Temáticos e Casuais. In: $3^{\mathbf{0}}$ Colóquio "Português Europeu e Português Brasileiro - Unidade e Diversidade na Passagem do Milénio". Lisboa: Universidade de Lisboa, set. 2002.

EMBICK, D. \& NOYER, R. Distributed Morphology and the Syntax/Morphology Interface. Ms, 2004.

FREEZE, R. Existentials and other locatives. Language 68(3), 1992. p. 553-595.

HARLEY, H. You're having me on: aspects of have. 1998. Disponível em http://linguistics.arizona.edu/ hharley. Acessado em: 22/08/2012

HENRIQUES, F. P. Construções com verbos de alçamento: um estudo diacrônico. Dissertação de Mestrado. Rio de Janeiro: UFRJ, 2008.

HUANG, J. On the distribution and reference of empty pronouns. Linguistic Inquiry 15, 1984. p 531-74.

JAEGGLI, O. \& SAFIR, K. The Null Subject Parameter and Parametric Theory. In: (orgs.) The Null Subject Parameter. Dordrecht: Kluwer, 1989. p. 1-44.

KATO, M. Sujeito e Tópico: duas categorias em sintaxe? In Cadernos de Estudos Linguísticos, 17, 1989. p.109 -132. \& DUARTE, M. E. L. Semantic and phonological constraints on the distribution

of null subjects in BP. In: NWAVE 32, Universidade da Pensilvânia, 2003. 
KATO, M. \& DUARTE, M. E.L Changes in the pronominal system in Brazilian Portuguese: the case of the third person. In: NWAV 34, New York, NYU, 2005.

\& DUARTE, M. E. L. Mudança paramétrica e orientação para o discurso. In: XXIV Encontro Nacional da Associação Portuguesa de Linguística, Braga, 2008.

MAGALHÃES, T. O sistema pronominal sujeito e objeto na aquisiçãodo português europeu e do português brasileiro. Tese de Doutoramemto. Campinas: Unicamp, 2006.

MARINS, J. O Parâmetro do Sujeito Nulo: uma análise contrastiva entre o português e o italiano. Dissertação de Mestrado. Rio de Janeiro: UFRJ, 2009.

MARTINS, A. M. \& NUNES, J. . Raising Issues in Brazilian and European Portuguese. In: Journal of Portuguese Linguistics, v. 4.2, p. 53-77, 2005.

MILSARK, G. (1974). Existential Sentences in English. Tese de Doutoramento. Cambridge, Mass, MIT, 1974.

PESETSKY, D. Zero Syntax: Experiencers and Cascades. Cambridge, Mass: The MIT Press, 1995.

PINTZUK, S. VARBRUL programs. 1988.

SANTANA, A. Estratégias pronominais de indeterminação: um estudo diacrônico. Dissertação de Mestrado. Rio de Janeiro: UFRJ, 2010.

SANTOS, D. de R. A ordem VS/SV com verbos inacusativos: um estudo diacrônico. Dissertação de Mestrado. Rio de Janeiro: UFRJ, Letras, 2008.

SOARES DA SILVA, H. O Parâmetro do Sujeito Nulo: confronto entre o português e o espanhol. Dissertação de Mestrado. Rio de janeiro: UFRJ, 2006.

SPANÓ, M. A ordem Verbo-Sujeito no Português Brasileiro e Europeu: um estudo sincrônico da escrita padrão. Tese de Doutoramento. Rio de Janeiro:UFRJ, 2008.

URIAGEREKA, J. From being to having: questions about ontology from a Kayne/Szabolcsi syntax. Working Papers in Linguistics 4, University of Maryland, 1996: 152-172. WEINREICH, U., LABOV, W. \& HERZOG, M. Empirical foundations for a theory of language change. In LEHMAN, W. \& MALKIEL, Y. (eds.) Directions for historical linguistics. Austin: University of Texas Press, 1968. p. 97-195.

Recebido em: 31/05/2013

Aceito em: 13/02/2014 